\title{
Does the St. Louis Equation Now Believe in Fiscal Policy?
}

\author{
KEITH M. CARLSON
}

$\mathbf{T}$ HE "St. Louis equation" was developed in 1968 in an article in this Review by Leonall Andersen and Jerry Jordan. ${ }^{1}$ The St. Louis equation is an estimated relationship (using the Almon procedure) between changes in total spending (GNP) and changes in the money supply and high-employment Federal expenditures. The focus of the Andersen-Jordan article was on the relative impact of monetary and fiscal actions. They rejected the propositions that the response of economic activity to fiscal actions relative to monetary actions was (1) larger, (2) more predictable, and (3) faster. In fact, their results suggested that the overall effect of fiscal actions was relatively small and not statistically significant. It was this result that generated considerable controversy among members of the economics profession. ${ }^{2}$ The conventional wisdom of the time was that fiscal actions (whether in the form of a maintained increase in expenditures or a tax cut) did have an impact on economic activity,

1Leonall C. Andersen and ferry L. Jordan, "Monetary and Fiscal Actions: A Test of Their Relative Importance in Economic Stabilization," this Review (November 1968), pp. $11-24$.

${ }^{2}$ No attempt is made here to give a complete bibliography on the St. Louis equation. Among the earlier articles, see Frank de Leenw and John Kalchbrenner, "Monetary and Fiscal Actions: A Test of Their Relative Importance in Economic Stabilization - Comment," this Review (April 1969), pp. 6-11; Richard G. Davis, "How Much Does Money Matter? A Look at Some Recent Evidence," Federal Reserve Bank of New York Monthly Review (June 1969), pp. 119-31, E. Gerald Cortigan, "The Measurement and Importance of Fiscal Policy Changes," Federal Reserve Bank of New York Monthly Review (June 1970), pp. 133-45; and Edward M. Granlich, "The Usefulness of Monetary and Fiscal Policy as Discretionary Stabilization Tools," Journal of Monet, Credit, and Banking (May 1971), pp. 506-32. with a multiplier usually estimated at about 1.5 or greater. ${ }^{3}$

In a recent article, Benjamin Friedman published updated estimates of the St. Louis equation. ${ }^{4}$ According to Friedman, the St. Louis equation now "believes in" fiscal policy. He presented results showing that the St. Louis equation yields a significant government spending multiplier of about 1.5 when estimated with data through second quarter 1976. This result conforms with neo-Keynesian thinking. At the same time, Friedman duly noted that with these updated estimates the relatively strong impact of monetary actions continues to hold.

The Friedman results are indeed interesting, and deserve closer examination. Those who accept the

${ }^{3}$ See, for example, Frank de Leeuw and Edward M. Gramlich, "The Federal Reserve-MTT Fconometric Model," Federal Reserve Bulletin (January 1968), pp. 11-40; James S. Duesenberry, Gary Fromm, Lawrence R. Klein, and Edwin Kuh, eds." The Brookings Quarterly Econometric Model of the United States (Chicago: Rand MoNally, 1965): Michael K. Evans and Lawrence $\mathrm{R}$. Klein, The Whaton Econometric Forecasting Model, 2nd Enlarged Edition (Philadelphia: University of Pennsylvaria, 1968); Maurice Liebenberg, Albert A. Hirsch, and Joel Popkin, "A Ouarterly Econometric Model of the United States: A Progress Report," Survey of Current Business (May 1966), pp. 425-56; and Daniel M. Suits, The Economic Outlook for 1969. Papers Presented to the Sixteenth Annual Conference on the Economic Outlook at the University of Michigan (Ann Arbor: University of Michigan, 1969), pp. $1-26$.

4Benjamin M. Friedman, "Even the St. Louis Model Now Believes in Fiscal Policy, Journal of Money Credit, and Banking, (May 1977), pp. 365-67. Also see William G. Dewald and Maurice N. Marchon, "A Modified Federal heserve of St. Louis Spending Equation for Canada, France, Germany, Italy, the United Kingdom, and the United States," forthcoming in Kredit und Kapital. 
original St. Louis evidence regarding the relative strength of monetary and fiscal actions do not question the importance of fiscal actions; sich actions do have economic impact over a certain period. However, the size of the steady-state multiplier is in dispute. In particular, past estimates of the St. Louis equation showed that there was a short-run impact for fiscal actions, but this impact washed out over time. If the fiscal action were accompanied by a change in the rate of monetary expansion, there would be an effect, but this would be attributable to the monetary action.

To deal with Friedman's results, the St. Louis equation is examined for the original sample period from 1953 through 1969 , and then compared with updated estimates through 1976 . On the basis of this examination, it is found that in light of developments since 1969, the form in which the original St. Louis equation was specified is no longer statistically appropriate. The St. Louis equation was originally estimated in arithmetic first difference form (with a constant). that is, all variables were defined as first differences in dollar amounts. Examination of the statistical properties of this specification indicates that at least one of the assumptions of least squares estimation appears to be violated when the experience from 1969 to 1976 is added to the data set. An alternative specification estimated with data through 1976 is offered which appears to satisfy the assumptions of least squares estimation, and in the process the original conclusions about the impact of fiscal actions are found to hold.

\section{UPDATING THE ORIGINAL ST. LOUIS EQUATION}

The original St. Lotis equation, as published in November 1968 , was estimated with data from I/1952 through 11/1968. A later version, published in April 1970, used $1 / 1953$ through $I V / 1969$ as the sample period. This second version served as the fundamental relation in the "St. Louis model." This model was an extension of the original St. Louis equation - extended to include determination of prices, output, unemployment, and interest rates.

There are several possible explanations of Friedman's results, including the effect of data revisions. Since the original presentation of the St. Louis equation, many data revisions have occarred. The net

\footnotetext{
5 Leonall C. Andersen and Keith M. Carlson, "A Monetarist Model for Economic Stabilization," this Review (April 1970), pp. $7-25$
}

Page 14 effect of these data revisions on the estimated coefficients is summarized in Table I. An update of the equation using revised data through 1976 is presented in Table II as a prelude to an examination of the factors contributing to the "appearance" of a signifcant fiscal multiplier.

\section{The Estimates}

In Table $I$, consider first a comparison of the St. Louis equation as published in April 1970 with a recent version estimated over the same original sam ple period. All constraints and the number of lags are maintained. At issue here is whether all the revisions of the National Income Accounts (NIA) and the money supply have altered the conclusions regarding the relative impact of monetary and fiscal actions drawn from the original St. Louis equation.

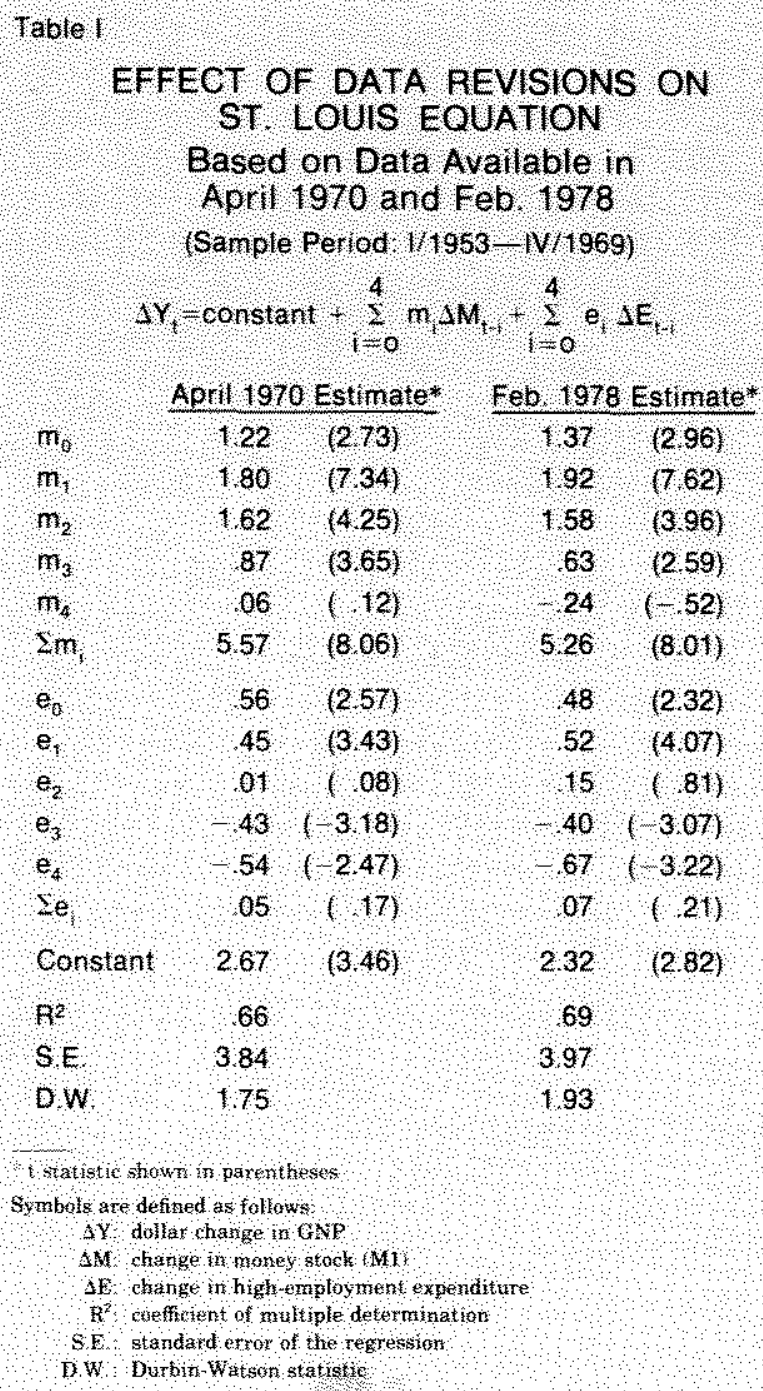


Table I indicates that the effect of all data revisions since April 1970 has been slight. The sum effect of monetary actions $\left(\Sigma m_{i}\right)$ is slightly smaller, but the pattern of time distribution among these coefficients continues to hold. Similarly, for fiscal actions, the effect of data revisions is very small. The sum effects on total spending of the independent variables continue to be dominated by the money variable. The summary statistics indicate a slightly larger $\mathrm{R}^{-1}$, an improved Durbin-Watson statistic, but a larger standard error of the regression. In general, there is nothing to indicate that data revisions have changed the fundamental conclusions drawn from the original St. Louis equation.

The equation was then estimated through 1976 , with 1953 maintained as the beginning of the sample period." These estimates are shown in Table II. The total effect of monetary actions continues to be important when the equation is estimated through 1976. The sum effect of monetary actions is somewhat smaller -4.48 for the period through 1976, compared with 5.26 for the earlier period. Probably the most

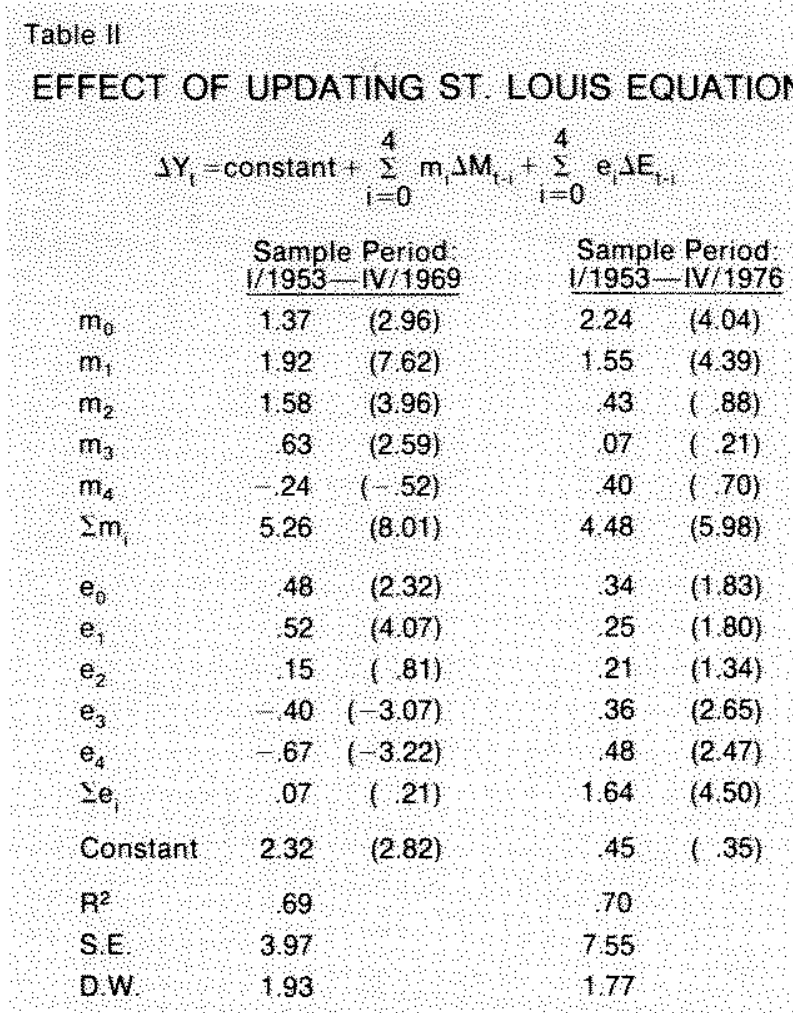

Al bymbols ard aborewatom are detened in table

GFriedman also gave estimates for the sample period beginning in I/1960. This was also done as a part of this study. How ever, none of the conclusions reached here was affected by this change in sample period. interesting feature of these updated estimates is that even though the sum effect of monetary actions did not appear to change much, the pattern of the lag distribution changed substantially. Originally the effect peaked for the change in money lagged one quarter $\left(\Delta \mathbf{M}_{1-\mathrm{B}}\right)$, but for the sample period extended through 1976 , the peak came on $\Delta M_{t}$, and only $\Delta M_{t}$ and $\Delta \mathrm{M}_{1-1}$ are significant.

Examination of the coefficients for the change in high-employment Federal expenditures $(\Delta \mathrm{E})$ indicates a much greater change for the updated version of the equation. The sum effect of fiscal actions climbed from .07 with data through 1969 to 1.64 with data through 1976. Furthermore, the $t$ statistic for the sum effect of fiscal actions is statistically significant in the 1953-76 regression. It is this result that Friedman emphasized.

\section{A Critique of These Updated Estimates}

To better understand what underlies these changed results, the error pattern of the St. Louis equation is examined in greater detail. This error pattern is shown in Chart $I$ for the equation as estimated for the original sample period through IV/1969, and for the updated version through IV $/ 1976$

The IV/1969 version shows extreme errors only for those periods associated with major strikes. Such is not the case, however, for the updated version. There are three periods that stand out $-\mathrm{I} / 1975$, III/1975, and $I / 1976$. The equation performs poorly in these periods, yet these quarters were not associated with major strikes.

A crucial assumption in linear regression is that the variance of the error term is constant. Examination of the errors for the period $1 / 1975$ through $I / 1976$ suggests that this assumption might be violated. If this is so, in the absence of collateral information about the relationship between the nonconstant error variances, the power of the standard $t$ and $F$ tests becomes indeterminate. ${ }^{\top}$ If, for example, these errors are positively correlated with the size of the deviation of the independent variables about their means, there is increased probability of incorrectly rejecting the null hypothesis of no significance. ${ }^{8}$ That is, a particular coefficient would be incorrectly judged to be significant.

TFor further discussion, see Jan Kmenta, Elements of Econometrics (New York: Macmillar, 1971), pp. 249-69.

${ }^{8}$ Ibid., p. 256 . 


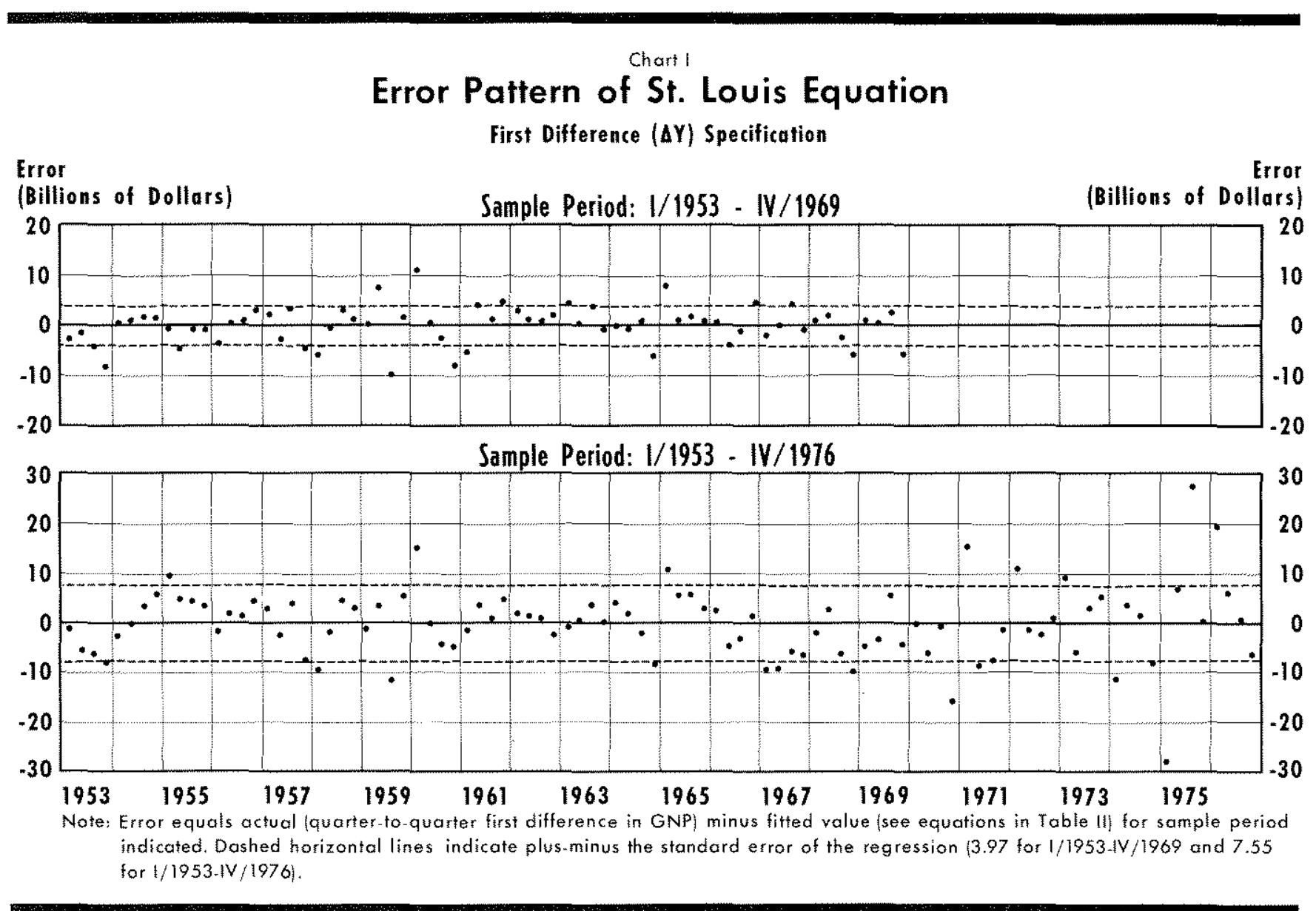

To determine if the assumption of constant variance in the error term is being violated, a statistical test was conducted for the sample period ending in IV/1969 and the one ending in IV/1976. These results are shown in Table III using the GoldfeldQuandt test for homoscedasticity. ${ }^{9}$ The assumption of homoscedasticity (constancy of error variances across all observations) is not rejected with this specification of the equation for the sample period ending IV $/ 1969$, but is rejected for the period ending IV/1976. In general, the St. Louis equation, as estimated in its original first difference form, but updated through 1976, does not now appear to satisfy the requirement of least squares estimation that the variance of the error term be constant. Given the evidence of nonconstancy of the error variances and the absence of reliable information about the relationship among the error variances, confidence in the significance of the estimated coefficients is reduced. One way around this problem is to seek an alterna-

9S. M. Goldfeld and R. F. Quandt, "Sone Tests for Homoscedasticity," Joumal of the American Statistical Association (June 1965), pp. 539-547. tive specification which satisfies this assumption of least squares. ${ }^{10}$

\section{AN ALTERNATIVE SPECIFICATION}

Updating the original St. Louis equation suggests the energence of statistical problems - problems which were not present when the equation was first estimated in 1968 and 1969. Rather than cling to that specification, an alternative is examined in an effort

${ }^{10} \mathrm{~T} 0$ determine the direction of the bias in the estimates of the standard error of the regression coefficients, the results from the 1976 regression were ranked according to the size of the independent variables and then grotped to compute error variances. Correlation of these error variances with the squared deviations of the group means from the overall mean yielded the following:

\begin{tabular}{ccc} 
& \multicolumn{2}{c}{ Correlation Coefficient } \\
\cline { 2 - 3 } & $\begin{array}{c}\text { 8 Groups of } \\
12 \text { Observations } \\
\text { Each }\end{array}$ & $\begin{array}{c}12 \text { Groups of } \\
8 \text { Observations } \\
\text { Each }\end{array}$ \\
& .90 & .55 \\
$\Delta \mathrm{M}$ & .83 & .67
\end{tabular}

These results, although not conclusive, suggest that the estimates of the standard errors are biased downward, that is, the associated $t$ statistics are biased upward. See Kmenta, p. 256 . 
Table

\section{RESULTS OF THE GOLDFELD QUANDT TEST FOR HETEROSCEDASTICITY}

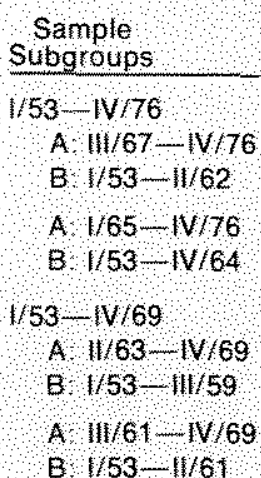

B. $1 / 53-11 / 61$

\section{Null: \\ Hypothesis}

$H_{0} V\left(\epsilon_{A}\right)_{A} v\left(\epsilon_{A}\right.$

$H_{f} v_{\left(C_{A}\right.}-\mathrm{V}\left(\epsilon_{\mathrm{B}}\right.$

$\mathrm{H}_{\mathrm{O}} \mathrm{V}\left(\mathrm{C}_{\mathrm{A}}-\mathrm{V}\left(\mathrm{e}_{\mathrm{S}}\right)_{\mathrm{S}}\right.$

$\left.H_{0}, v_{\epsilon}\right)_{A}-\mathrm{V}(\epsilon)_{B}$
( 1 Version of Equation)

\section{Alternatwe}

Hypothesis:
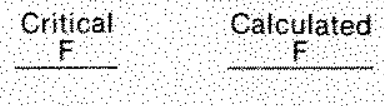

Test

Besult
$H_{a}, V\left(e_{A}\right)_{A}>V / f_{B}$

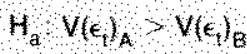

$\left.F_{(01)}, 35\right)=224$

$\mathrm{F} 357$

$\mathrm{H}_{0}$ rejected

$F_{1014545)^{-202}}$

$F-530$

$\mathrm{H}_{\mathrm{a} \text { ejected }}$

$H_{\alpha} \vee\left(s_{A}>v_{\epsilon}\right)_{\mathrm{B}}$

$\mathrm{F}_{0}(24,4) 266$

$F=89$

H, not elected

$\left.\left.H_{A} v_{l}\right)_{A}, v_{(c}\right)_{B}$

$8=46$

$H_{0}$ not rejected

\section{Symtion}

Ve earance on tesduls

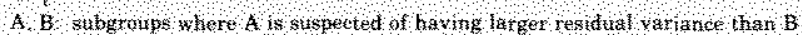

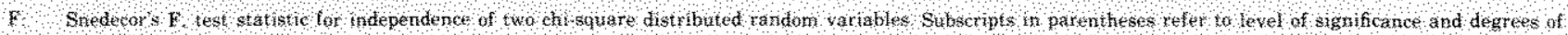
ftedonm numerater and detemmatar

to avoid these specification problems. ${ }^{11}$ The alternative chosen here is to express all variables in the equation in rates-of-change form. ${ }^{12}$

In their original article, Andersen and Jordan sug. gested that a rate-of-change specification might be preferable. $^{13}$ At that time both specifications gave essentially the same results with regard to the relative impact of monetary and fiscal actions. They opted for the first difference form because it gave direct estimates of multipliers which, at the time, were more commonly used than elasticities in summarizing the economic impact of changes in policy variables.

11There are various methods of avoiding the statistical problems discussed here, so it camot be said with certainty that the alternative specification chosen here is "the correct one." However, if an alternative is found to satisfy the assumption of homoscedasticity, along with the other assumptions of least squares, more confidence can be placed on the estimated regression coefficients from that specification than in the original one.

12Since the primary problem with the arithmetic first difference (including a constant) specification seems to be one of heteroscedasticity when the sample period is extended through 1976, an attempt was made to identify the source of the problem. To see whether a specification error may be the source of the problem, the Brown-Durbin-Evans test for constancy of the regression coefficients over time was applied to the first difference specification. The hypothesis of constancy of the coefficients was not rejected for the original sample period, but rejected for the extended period. However, for the rate-of-change specification, the hypothesis of constancy of the coefficients was accepted for both the original and extended sample periods. See R. L. Brown, J. Durbin, and J. M. Evans, "Techniques for Testing the Constancy of Regression Relationships Over Time, with Comments," Joumal of the Royal Statistical Society, Ser. B (1975), pp. 149-92.

${ }^{13}$ Andersen and Jordan, "Monetary and Fiscal Actions," fn. 10, p. 16.

\section{The Estimates}

Estimates of the St. Louis equation in rate-ofchange form for the two sample periods are shown in Table IV. The pattern of estimated coefficients as the

Tabte iv

\section{ALTERNATIVE SPECIFICATION OF} ST. LOUIS EQUATION

\begin{tabular}{|c|c|c|c|}
\hline \multicolumn{2}{|c|}{$\begin{array}{l}\text { Sample Perlod } \\
/ / 1953-\text { V/1969 }\end{array}$} & \multicolumn{2}{|c|}{$\begin{array}{l}\text { Sample Period } \\
1 / 1959 \text { WV/1976 }\end{array}$} \\
\hline 30 & $(206)$ & 40 & $(2.96)$ \\
\hline 47 & $(5.90)$ & 41 & $(5.26)$ \\
\hline 38 & $(3.01)$ & 25 & $(2,14)$ \\
\hline .09 & $(1,19)$ & 06 & $(271)$ \\
\hline 16 & $(-1.10)$ & -.05 & $(-37)$ \\
\hline 1.08 & $(495)$ & 1.06 & $(5.59)$ \\
\hline 07 & $(1,77)$ & .08 & $(2.26)$ \\
\hline .09 & $(3,63)$ & 06 & $(2.52)$ \\
\hline .03 & $(.75)$ & 00 & $(.02)$ \\
\hline-.09 & $(-3.68)$ & .06 & $(-2.20)$ \\
\hline-16 & $(-4.07)$ & 07 & $(-183)$ \\
\hline$\therefore 06$ & $(-88)$ & .03 & $(40)$ \\
\hline 3.22 & $(4.04)$ & 269 & $(323)$ \\
\hline 53 & & 40 & \\
\hline 325 & & 3.75 & \\
\hline 185 & & 1.78 & \\
\hline
\end{tabular}

All symbols and abmeviatians are tefined in Table 1 except the dot twer Yarkable stgnifes compounded aniual rate of thange. 


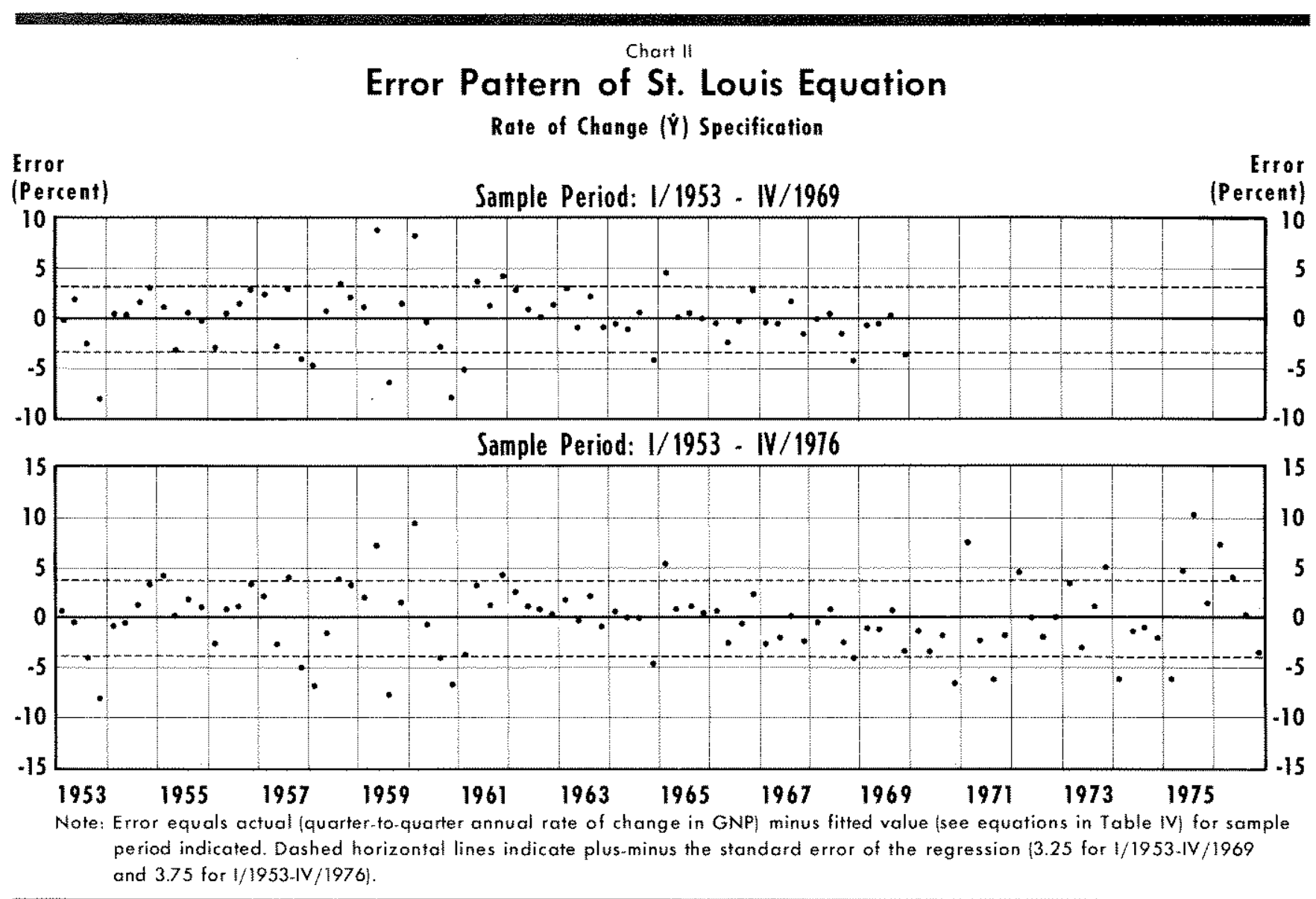

equation is updated differs substantially from thọse presented for the first difference form in Table II. The sum effect of both monetary and fiscal actions changes little. Although there is some bunching of the coefficients towards $t=0$, the coefficient on $\dot{M}_{2-1}$ is still the peak quarter of effect.

Examination of the estimates of the fiscal effect indicates that the sum effect changes from negative to positive as this specification is updated. However, the total of the fiscal effect is not significantly different from zero for either the original or extended sample periods. The distribution of the lag coefficients is little changed as the equation is updated through 1976, in contrast to the first difference specifications in Table II.

\section{Analysis of the Error Pattern}

The results of updating the St. Louis equation in rate-of-change form differ substantially from those in first difference form (Chart II). Using rates of change instead of first differences appears to satisfy the assumption of constant error variances. The results of the Goldfeld-Quandt test are shown in Table V. For each of the test periods, the null hypothesis of constancy in the error variances is not rejected. By reason of this argument, there is no reason to suspect bias in the estimated standard errors for this specification. The sum effect for the monetary variable is significant, but for the fiscal variable it is not.

\section{SUMMARY AND CONCLUSION}

Benjamin Friedman has published results showing that the St. Louis equation now "believes in" fiscal policy. This conclusion was based on updated estimates of the equation in its originally published first difference form. Friedman's conclusion is shown to be suspect on statistical grounds. Estimation of that equation in arithmetic first difference form no longer appears to be acceptable because there is evidence of nonconstant error variance. Hence, it is difficult to assess the statistical reliability of any conclusions about the impact of monetary and fiscal actions based on estimates with that form of the equation.

To correct these statistical problems, the St. Louis equation was reestimated in rate-of-change form. All other properties of the specification were maintained, 


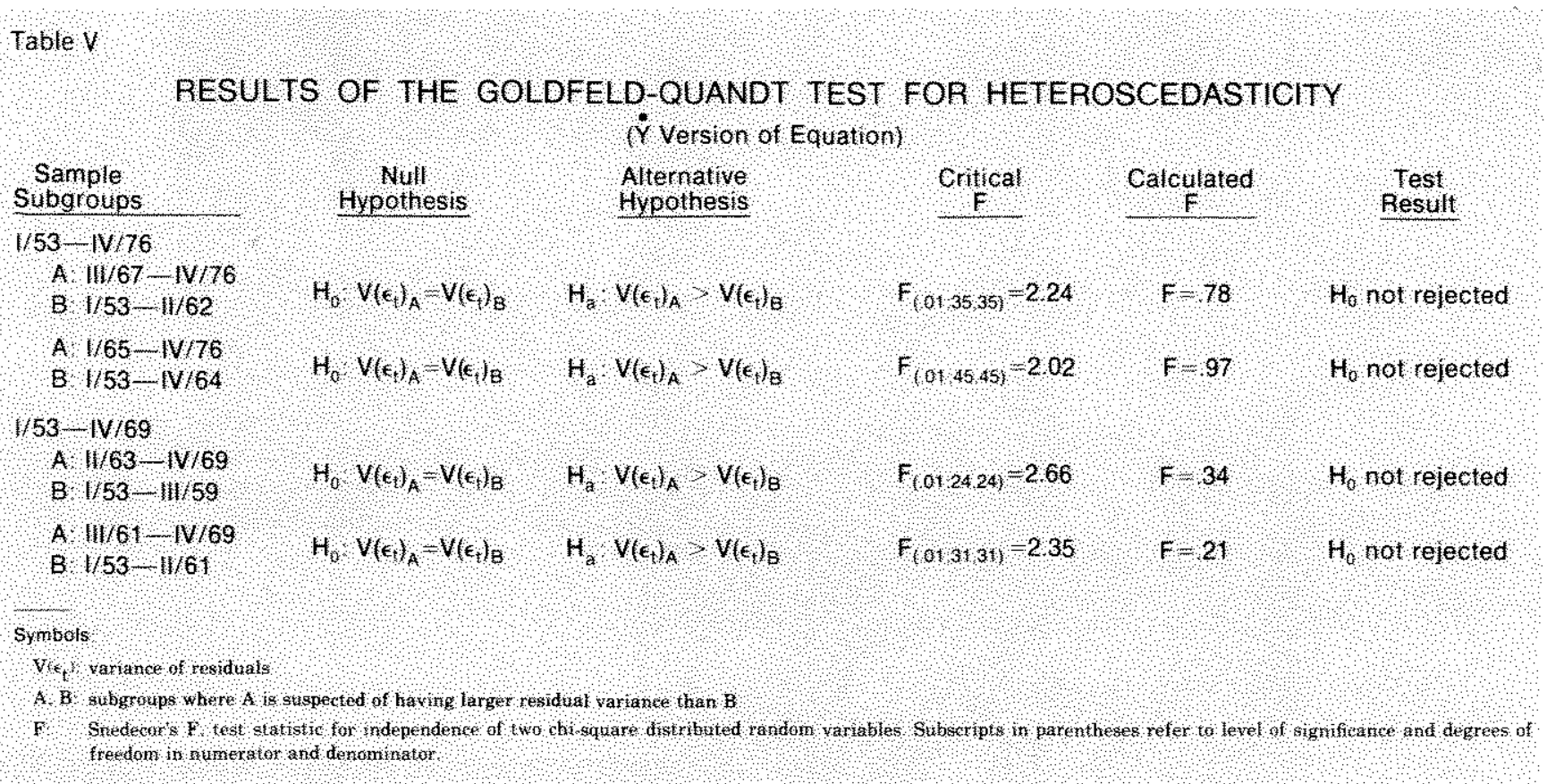

that is, the number of lags, the constraints and degree of polynomial, and the definitions of the variables. This alternative specification satisfied the least squares assumptions concerning constancy in the error variance. With this rate-of-change alternative preferred on statistical grounds, the original empirical conclusion regarding the steady-state effect of fiscal. actions was not altered. The evidence does not support the contention that the St. Louis equation now "believes in" fiscal policy.

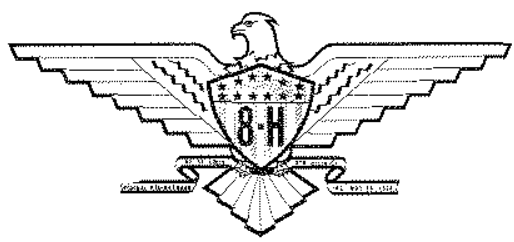

